\title{
Kulturna participacija stanovnika novih stambenih prostora u zagrebačkoj mreži naselja
}

\author{
Mirjana Adamović \\ Institut za društvena istraživanja u Zagrebu, Hrvatska \\ e-mail:mirjana@idi.hr
}

\begin{abstract}
SAŽETAK Koristeći Bourdieuov teorijski okvir, rad nastoji istražiti strukturu kulturne participacije i njenu povezanost sa socijalnim obilježjima ispitanika koji stanuju u novim stambenim naseljima i lokacijama u Zagrebu i susjednim gradovima (Samoboru, Velikoj Gorici i Zaprešiću). Anketno istraživanje provedeno je 2014. godine na ciljanom uzorku od 308 ispitanika. Faktorskom analizom identificirana su četiri obrasca kulturne participacije: „participacija u visokoj kulturi“, „čitanje i konzumacija kulturnih programa“, „aktivno bavljenje umjetničkim i primijenjenim aktivnostima“ i obrazac „auditivna kultura“. Kako bi se ustanovio utjecaj odabranih sociodemografskih obilježja, faktori su pretvoreni u aditivne skale, na kojima je provedena analiza varijance i t-test. Sa skalom „participacija u visokoj kulturi“ povezani su obrazovanje, radni status, zanimanje ispitanika te prosječni mjesečni prihod kućanstva. Sa skalom „čitanje i konzumacija kulturnih programa“ povezani su ženski spol, dob, obrazovanje i bračni status, a sa skalom „aktivno bavljenje umjetničkim i primijenjenim aktivnostima“ povezan je od svih obilježja samo ženski spol. Skala „auditivna kultura“ nije povezana ni $s$ jednim sociodemografskim obilježjem. Ovo istraživanje potvrđuje važnost socioekonomskog statusa za potrošnju visoke kulture te važnost roda u objašnjenju pojedinih oblika kulturne participacije. Razlika u kulturnoj participaciji stanovnika grada Zagreba i stanovnika susjednih gradova nije se utvrdila.
\end{abstract}

Ključne riječi: kulturna participacija, kulturni kapital, nova stambena naselja i lokacije, rod. 


\section{Teorijske postavke kulturne participacije}

Jedna od najutjecajnijih teorija u objašnjenju kulturne participacije jest Bourdieuova teorija kulturnog kapitala1 (Bourdieu, 2011. [1979./1982.]). Temelj kulturnog kapitala nalazi se u obitelji, a ona određuje ranu kulturnu socijalizaciju. Bourdieu kaže kako su „kulturne potrebe proizvodi odgoja: [...] sve kulturne prakse (posjećivanje muzeja, koncerata, izložaba, čitanje itd.) sklonosti u književnosti, slikarstvu ili glazbi usko [su] povezane s razinom obrazovanja (mjerenom prema školskom naslovu ili broju godina školovanja), i u drugom redu, s društvenim podrijetlom" (2011.:5). Kulturna je socijalizacija klasno određena, te klase koriste svjesno ili nesvjesno različite kulturne strategije kako bi osigurale prestiž ili čast. Imajući u vidu Bourdieuova saznanja o distinkciji između različitih društvenih stratuma, kulturna konzumacija reflektira i podržava granice između različitih klasa. Najočitija akumulacija kulturnog kapitala vidljiva je u načinu kulturne potrošnje i društvenim vezama ljudi višeg socioekonomskog statusa (Kane, 2004.; Christin, 2012.).

U nastojanju da odredi način formiranja estetskog ukusa Bourdieu kaže kako formalno obrazovanje (jezični instrumenti i referencije) nije dostatno za razvijanje estetskog iskustva, nego postoji „ovisnost estetske dispozicije o prošlim ili sadašnjim materijalnim uvjetima života, koji su uvjet i njezina ustanovljenja i njezine praktične primjene i istovremeno akumulacije kulturnog kapitala“, koji se stječe „samo pod cijenu neke vrste povlačenja izvan ekonomske nužde“ (Bourideu, 2011.:50). Time Bourdieu naznačuje kako se u pozadini praćenja ostvarenja visoke kulture nalazi klasno određenje koje podrazumijeva „buržoasko iskustvo svijeta“. Ekonomska moć omogućava ostavljanje ekonomskih potreba po strani, što se oživotvoruje u polju kulture kao materijalna ili simbolička potrošnja umjetničkog djela kao „jedno od najviših očitovanja lagodnosti" (Bourdieu, 2011.:51).

Istraživanjima je utvrđeno kako su svi tipovi kulturnih aktivnosti povezani s višim obrazovanjem (Kane, 2004.:113). Osim formalnog obrazovanja i društvenih veza, koje su povezane s elitnim muzičkim preferencijama (klasična glazba, opera), važnom varijablom u suvremenim istraživanjima kulturne participacije pokazuje se i geografska mobilnost kao i neformalno umjetničko obrazovanje, koje ima utjecaja na profiliranje visokog muzičkog ukusa (Relish, 1997.).

Bourdieuova teorija doživjela je određene kritike: npr. neki autori smatraju kako je previše naglasio porijeklo, a zanemario utjecaj društvene okoline te da nije u dovoljnoj mjeri uzeo u obzir pojedinačne mreže i iskustva te njihovu važnost u gradnji kulturnih resursa (Upright, 2004.; Kane, 2004.).

1 Bourdieu razlikuje socijalni, ekonomski i kulturni kapital. Kulturni i socijalni kapital sredstva su društvene produkcije i reprodukcije, kao i ekonomski kapital, a klase i klasne frakcije razlikuju se prema tome koliko i kakvog kapitala posjeduju (Čolić, 2002.:89). Kulturni kapital egzistira u trima formama: kao utjelovljen (npr. trajne dispozicije uma i tijela), objektiviran kroz formu kulturnih dobara (slika, knjiga, instrumenata itd.) i u institucionaliziranoj formi (npr. obrazovne kvalifikacije) (Bourdieu, 1986.). 
Istraživanja tipova kulturnih preferencija ukazala su na pojavu novih oblika kao što su tzv. kulturni omnivori (svejedi), odnosno ljudi koji pokazuju interes za konzumaciju i visoke i popularne kulture (Kane, 2004.; Peterson i Kern, 1996.). Naime došlo je do kvalitativne promjene ukusa visokih društvenih slojeva, koji sve više iskazuju eklekticizam, odnosno zainteresirani su ne samo za visoko-statusne (engl. high-brow) nego i za srednje-statusne (engl. middle-brow) i niže-statusne (engl. lowbrow) kulturne aktivnosti. Razlozi zbog kojih je došlo do promjene ukusa visoke klase, koji je, između ostaloga, uključivao i snobizam² spram konzumiranja različitih kulturnih sadržaja (omnivorizam), Peterson i Kern (1996.) nalaze u pet temeljitih promjena kroz koje su prošla zapadna društva: strukturne promjene, promjene vrijednosti, promjene svijeta umjetnosti, generacijske promjene i promjene politike statusnih grupa. Od razloga strukturne prirode koji su liberalizirali dostupnost estetskog ukusa elita širim slojevima društva autori navode porast kvalitete života, porast broja obrazovanih, migracijske procese i mobilnost društvenih klasa. Sveprisutnost medija također je pomogla inauguraciji ukusa različitih klasa, pa je postalo sve teže izolirati većinu stanovništva od onih koji oblikuju elitni estetički ukus. Pozivajući se na radove Ingleharta iz 1990. i Abramsona i Ingleharta iz 1993. godine, Peterson i Kern (1996.:905) kažu kako je u prošlom stoljeću došlo do historijskih promjena u vrijednostima jer su esencijalističke vrijednosti zamijenjene tolerantnijim vrijednostima, posebno onima koje se tiču spolova, etniciteta, rasa i religija. Nadalje, dolazi do promjena u svijetu umjetnosti. Tržište je utjecalo na sve umjetnosti na način da je počelo tragati za novim i avangardnijim oblicima izražavanja, pa konkurenti na umjetničkom tržištu postaju umjetnici iz cijelog svijeta, čija se djela neprestano kritički prosuđuju. Tako je stvorena estetska osnova za pomak od „elitističkog ekskluzivnog snoba“ prema „elitističkom inkluzivnom omnivoru“. Došlo je i do generacijskih promjena, što se pogotovo ogleda u praćenju glazbe. Ranije je bilo prirodno da s prelaskom iz mlađih u starije generacije dolazi do promjene ukusa, i to od pracenja pop glazbe prema praćenju ozbiljnijih žanrova. Novije generacije, oblikovane događajima kao što je to bio, između ostaloga, Woodstock, svoj estetski ukus nisu shvatile kao fazu u odrastanju, nego kao alternativu high-brow kulturi te kao potrebu za otvorenošću raznim žanrovima. Što se politike statusnih grupa tiče, najveća se promjena dogodila u tome što je snobizam i njegovo isključivanje bio „efikasan marker statusa“ i vrijednosti ranijih, viših poduzetničkih klasa. Vrijednosti omnivora više su otvorene globalnom svijetu i pokazuju poštovanje prema vrijednostima drugih kultura, što se uklapa u afinitete novih klasa, npr. poduzetničko-administrativne.

Pojava eklekticizma u kulturnim preferencijama teorijski se tumači dvojako: za neke je eklekticizam doveo u pitanje Bourdieuovu tezu o kulturnom životu kao klasnoj distinkciji, a za druge se njegovom pojavom samo potvrdio jaz između visokih i srednjih klasa u odnosu na niže klase, koje imaju slabe mogućnosti participiranja u sadržajima visoke kulture. Osim toga u nizu recentnih istraživanja pojavila se debata

2 U definiciji snobizma Peterson i Kern (1996.) koriste određenje Levinea iz 1988. godine, prema kojem je snobizam neparticipiranje u srednje-statusnim (middle-brow) ili niže-statusnim (low-brow) kulturnim aktivnostima, a participiranje isključivo u visokim, elitnim kulturnim aktivnostima. Snobizam je prema uvidima navedenih autora bio slabo zastupljen u SAD-u u razdoblju 1982. - 1992. godine. 
oko novih modela distinkcija, prema kojima se preferencije za sustav visoke kulture zamjenjuju „kozmopolitskim“ kulturnim kapitalom, čiji su akteri mlađe, obrazovane grupe, a čiji stil života podrazumijeva praćenje suvremene glazbe, društvenih medija, vježbanje i takav stil društvenog života koji se ne uklapa u kanone visoke kulture (Miles, 2016.:183).

Analiza istraživanja kulturne participacije pokazuje stalni spoznajni i metodološki napredak, iako još ni danas ne postoje precizne i općeprihvaćene definicije kulturne participacije kao ni odgovori na pitanje o tome kada netko prestaje biti pasivan, a kada postaje aktivan participant (UNESCO, 2012.). Prema UNESCO-u, kulturna je participacija dio svakodnevnog života i ne odnosi se samo na konzumaciju produkata koji spadaju u područje tzv. visoke ili elitne kulture, ona može biti receptivna ili kreativna, te kao takva pridonosi kvaliteti života (UNESCO, 2012.:17). Osim toga kulturna participacija dio je šireg „holističkog participacijskog kapaciteta“ otvaranja drugim socijalnim grupama (UNESCO, 2012.:72). UNESCO upućuje na nastale brojne participacijske modele koji se mijenjaju zajedno s razvojem novih tehnologija (socijalne mreže, internetska komunikacija). Ti mediji proširuju područje kulturne participacije pogotovo onim ljudima kojima kultura nije svakodnevno dostupna (osobe s posebnim potrebama, samohrani roditelji, neke etničke grupe, osobe iz ruralnih područja i sl.) (UNESCO, 2012.:25). Kulturna participacija nije, dakle, samo pitanje mjerenja toga što ljudi konzumiraju ili kako se angažiraju u spektru kulturnih aktivnosti (publika, izvođači, umjetnici), nego se sve više povezuje s pitanjima identiteta i samorazvoja. Iako se čini kako kulturna participacija ima puno toga zajedničkog s društvenim uvjetima, ona je u prvom redu kompleksna aktivnost koja uključuje različite društvene interakcije. U skladu s navedenim promjenama neki autori pozivaju na promjenu metodologije kojom se prati kulturna participacija s obzirom na to da je došlo do radikalne redefinicije sustava visoke kulture (Miles, 2016.). Također se upozorava kako se uska definicija kulturne participacije fokusirana na precizno definirane participacijske forme ne može nositi s pojavom novih oblika prisutnih u svakodnevnom životu (Miles, 2016.).

\section{Kulturna participacija i rod}

Rodni karakter kulturne reprodukcije bio je donedavno neopravdano zanemaren jednako kao i društvene veze koje doprinose distribuciji kulturnog kapitala. Istraživanja su uglavnom bila koncentrirana na utjecaj socioekonomskog statusa na kulturni kapital (DiMaggio, 2004.), što je očekivano s obzirom na to da je većina inspiraciju tražila u Bourdieuovim istraživanjima, koji je ženama priznao veću sklonost umjetničkom, međutim za njega je klasna pripadnost imala veću težinu od spola (Kane, 2004.:119). No danas već postoji konsenzus prema kojem je rod esencijalna determinanta kulturne participacije, barem što se tiče participiranja žena u visokoj kulturi (Christin, 2012.). Žene su konzumentice visoke kulture više nego muškarci, i u tom je primjeru rodna distinkcija važnija od klasne pripadnosti (DiMaggio, 2004.; Kane, 2004.; Christin, 2012.). Rezultati istraživanja DiMaggia i Mukhtara (2004.) na primjeru umjetničke participacije kao kulturnog kapitala u SAD-u, u razdoblju od 1982. do 2002., ne upućuju na defeminizaciju. 
Iako Christin (2012.) smatra kako socioekonomski pokazatelji ne mogu do kraja objasniti tu povezanost, mnogi tumače kako su promjene u obrazovnoj strukturi, zapošljavanju žena, visini zarada kao i rad žena na razvoju vlastitih karijera tomu pridonijele. Iz takvog socioekonomskog tumačenja participacija žena mogla bi biti primjer modela „kulturne mobilnosti“, što znači da kulturni kapital mogu iskoristiti i djeca/djevojčice iz obitelji nižeg statusa ukoliko su izloženi umjetničkim aktivnostima. Na primjer, istraživanje nivoa kulturne participacije žena u umjetnosti pokazuje kako, za razliku od muškaraca, žene iz srednje klase tom participacijom često nadmašuju društvene karakteristike svoje klase (obrazovni nivo, zanimanje i zaradu). Međutim neki rezultati pokazuju kako je za tumačenje participacije žena bitno kakvog je obrazovanja otac, pri čemu je ustanovljena pozitivna povezanost između kulturne participacije žena i razine obrazovanja njihovih očeva. Stoga na djelu može biti i model „kulturne reprodukcije“, dok za muškarce ipak prije vrijedi model „kulturne mobilnosti“ (Christin, 2012.). U svakom slučaju, kulturna participacija ne može se objasniti isključivo iz perspektive individualnih postignuća jer je to pojednostavljeno objašnjenje (DiMaggio, 2004.).

DiMaggio (2004.) i Tepper (1998.) upozoravaju kako je razumijevanje podjele poslova u kući nužno i za razumijevanje podjele kulturnog rada unutar obitelji, pri čemu su žene te koje su zadužene za kulturni rad, odnosno kulturnu reprodukciju obitelji. Razdvajajući žene i muškarce Upright (2004.) tvrdi, temeljem znanstvenog rada Collinsa iz 1988. i 1992., kako su žene više angažirane oko (weberijanskog zadatka) pretvorbe klase u status u području kulture, dok su muškarci više uključeni u klasnu stvarnost i pitanja produktivnosti. U tako postavljenoj privatno/javnoj podjeli rada žene se više od muškaraca brinu o statusnom nivou obitelji i njezinoj javnoj prezentaciji. Obitelji nižih i srednjih klasa naročito se trude poticati djevojčice i djevojke na bavljenje kulturnim aktivnostima, što dovodi do različite kulturne socijalizacije u odnosu na dječake (Tepper, 1998.; Upright, 2004.), a rezultira svojevrsnom prednosti žena pred muškarcima (Christin, 2012.). Kako pak s višim obrazovanjem dolazi do oblikovanja višeg estetskog ukusa, ženski obrasci kulturne participacije manje se transformiraju nego obrasci kulturne participacije muškaraca. Žene, primjerice, znatno više participiraju u svim tipovima kulturnih aktivnosti, izuzev u praćenju koncerata džez glazbe, također češće posjećuju muzeje i galerije, pohađaju koncerte klasične glazbe, opere i plesne predstave (Upright, 2004.).

\section{Kulturna participacija i prostor}

Kada je Bourdieu pisao o stilu života u području kulture, upozorio je na činjenicu kako postoji raspodjela grupa u društveno hijerarhiziranom geografskom prostoru (2011.:113). Žarišta ekonomskih i kulturnih vrijednosti nalaze se u metropolama, kaže Bourdieu, i u njima se koncentriraju najveća financijska sredstva za održavanje kulturnih događanja. Ipak, prostor je ostao relativno neistražen u području kulturne participacije (Brook, 2016.; Cutts i Widdop, 2016.; Leguina i Miles, 2017.), iako se različite razine participacija vežu upravo uz različite prostore.

S razvojem javnih politika socijalne inkluzije na europskom nivou sve se više govori o nepravednoj geografskoj distribuciji kulturnih dobara kao i potrebi eliminiranja nejednakosti u tom kontekstu. Osnovna pitanja koja se postavljaju u vezi odnosa 
kulture i prostora su: pogoduje li blizina središtima kulturnih događanja učestalosti njihove potrošnje; kakva je pozicija prostora u odnosu na ostale varijable koje su važne za tumačenje konzumacije kulture kao što su obrazovanje i klasa; tko su akteri prostornih nejednakosti, tj. pogađa li nejednaka prostorna distribucija kulturnih dobara na isti način sve društvene grupe?

Brook (2016.) je u svojem istraživanju utvrdila kako nivo opskrbljenosti prostora kulturnim dobrima nije jednostavno povezan s njihovim posjećivanjem. Međutim unapređenje prostornog pristupa kulturnim dobrima može imati utjecaj na frekvenciju konzumacije; u Londonu je ustanovljeno kako najviši nivo konzumacije kulturnih događanja postoji među obrazovanim, bijelim ispitanicima koji imaju dobar pristup kulturnim dobrima. Dapače, istraživanje Brook iz 2013. godine govori u prilog tome da su prostorne varijable bolji prediktori odlaska na operne koncerte nego sociodemografski (Brook, 2013.). Prostorna pitanja vežu se i uz nove stilove kulturne potrošnje, kao što su to već spominjani omnivori, za koje su recentna istraživanja utvrdila postojanje različitih tipova u specifičnim kulturnim poljima (Cutts i Widdop, 2016.:2). Primjerice „proždrljivi omnivori“ koncentrirani su u jednom prostornom klasteru (unutrašnjost grada Londona), a riječ je o pojedincima s visokim obrazovanjem i njemu srodnim zanimanjima, iako ima malo dokaza da pripadaju mlađim dobnim kohortama (skupinama) (Cutts i Widdop, 2016.). Nadalje, sve složenija istraživanja kulturne participacije pokazuju na primjeru knjižnica kako su ljudi više skloni posuđivati knjige iz knjižnica koje se nalaze u blizini drugih atraktivnih prostora kao što su dućani, škole ili banke, čime se pokazuje koliko bi kulturna politika mogla biti povezana s urbanim planiranjem (Delrieu i Gibson, 2017.). U zemljama u kojima ne postoji policentrični kulturni razvoj razložno je govoriti o razlici između mjesta prebivanja i održavanja kulturnih događaja s obzirom na to da se većina kulturnih događanja održava izvan lokalnih zajednica (UNESCO, 2012.:23). U Hrvatskoj, na primjer, razvijenost i urbaniziranost prostora važni su činitelji kulturne participacije, pa tako višu kulturnu potrošnju imaju Zagreb i okolica, kao i primorski dijelovi Hrvatske od ostalih hrvatskih regija (Tonković, Marcelić i Krolo, 2017.).

Novi trendovi pokazuju kako se narav kulturne participacije promijenila zahvaljujući pojavi globalnog prostora, u kojem potrošnja kulturnih sadržaja s obzirom na mjesto nastanka postaje sve fluidnija, te se kulturni prostor značajno reinterpretira u globalnom kontekstu (Švob-Đokić, 2010.).

\section{Uzorak i metoda istraživanja}

Istraživanje, na čijim se rezultatima temelji ovaj rad, provedeno je 2014. godine u okviru projekta ${ }^{3}$ kojem je osnovna tema bila kvaliteta života i stanovanja u novim

3 Projekt „Kvaliteta života u novostambenim naseljima i lokacijama u zagrebačkoj mreži naselja" proveden je u okviru Instituta za društvena istraživanja u Zagrebu u periodu 2014. 2016. godine. Vidjeti više o rezultatima u publikaciji Svirčić Gotovac, A. (2015). New Housing Estates in the Settlement Network of Zagreb - Community Infrastructure. U: Svirčić Gotovac, Anđelina i Zlatar, Jelena (Ur.) (2015). Kvaliteta života u novostambenim naseljima i lokacijama u zagrebačkoj mreži naselja, Zagreb, Institut za društvena istraživanja u Zagrebu, 191 str. 
naseljima izgrađenima nakon 1990. godine u Zagrebu i zagrebačkoj mreži naselja. Uzorak je obuhvatio 308 ispitanika iz kućanstava u novostambenim naseljima i lokacijama u Gradu Zagrebu i u tzv. satelitskim gradovima Zagrebačke županije (Samobor, Velika Gorica i Zaprešić). U uzorku su zastupljeni ispitanici s 23 mikrolokacije: 17 lokacija iz Grada Zagreba i po dvije lokacije iz spomenutih gradova Zagrebačke županije. Svakako treba napomenuti kako u Zagrebu ima malo potpuno novih naselja, kakva su npr. Sopnica-Jelkovec ili ostala tzv. POS-ova naselja ${ }^{4}$, te je ponajprije riječ o novim stambenim zgradama sagrađenima u centralnim ili u dijelovima starijih naselja po principu pogušćivanja te naslanjanja na postojeću infrastrukturu (tramvajska pruga, škole, vrtići, shopping-centri itd.). Može se reći kako je uzorak bio „ciljanog ili namjernog tipa“ (Krištofić, 2015.:132), tako da nema karakteristike reprezentativnog uzorka, osim prema spolu (48,1\% muškaraca i 51,9\% žena). Istraživanje je provedeno anketnim upitnikom koji je uz kvalitetu stanovanja ispitivao i neke odrednice aktivne i pasivne kulturne participacije. Po svojim odrednicama to je bilo svojevrsno pilot-istraživanje, koje može dati smjernice za buduća istraživanja na reprezentativnim uzorcima, a čiji bi se rezultati mogli generalizirati na populaciju.

Cilj rada istražiti je kulturnu participaciju stanovnika novostambenih lokacija. Istraživačka pitanja od kojih se pošlo bila su: „Kakve je učestalosti i strukture kulturna participacija?“, „Postoje li razlike u kulturnoj participaciji s obzirom na rod te rezidencijalni status?“, „Koja su još sociodemografska obilježja povezana s obrascima kulturne participacije?"

U skladu s teorijskim okvirom očekuje se kako će istraživanje potvrditi postojanje različitih obrazaca u konzumaciji kulturnih sadržaja te kako će pojedine sociodemografske karakteristike (u prvom redu obrazovanje i rod) biti povezane s kulturnom participacijom.

S obzirom na značenje rezidencijalnog statusa očekuje se kako će doći do diferencijacije između stanovnika Zagreba i stanovnika ostalih (satelitskih) gradova Zagrebačke županije s obzirom na mogućnost (dostupnost) konzumacije visokih kulturnih sadržaja.

U istraživanju se pošlo od pretpostavke o postojanju aktivne i pasivne kulturne participacije (Brook, 2011.; UNESCO, 2012.), pri čemu se pod pasivnom participacijom podrazumijevalo „a) posjećivanje kulturnih priredaba (kazališnih izvedaba, kina, koncerata, muzeja i galerija), b) čitanje knjiga, časopisa i novina, c) gledanje televizije, d) gledanje video/filmova, e) slušanje radija“, dok se aktivna participacija odnosila na sudjelovanje u radu ,amaterskih kazališta, amaterskih orkestara, recitatorskih, literarnih i sl. grupa, folklornih grupa i sekcija, likovnih radionica i udruga kulturno-umjetničkog amaterizma“ (Katunarić i Cvjetičanin, 1998.:83). U ak-

${ }^{4}$ Riječ je o stambenom naselju u istočnom dijelu Grada Zagreba sagrađenom u okviru programa društveno poticane stanogradnje. Izgradnju i prodaju stanova organizirao je Grad Zagreb. Poznato POS-ovo naselje još je i Špansko-Oranice u zapadnom dijelu grada Zagreba, a u ukupnom uzorku njihov je udio iznosio manje od 10\%. 
tivnu participaciju ubrojili smo i bavljenje primijenjenim kulturnim aktivnostima kao i neformalno umjetničko obrazovanje. Učestalost kulturne participacije mjerena je Lickertovom ljestvicom peterostupanjskog tipa ( 1 - nikada, 2 - nekoliko puta godišnje, 3 - nekoliko puta mjesečno, 4 - nekoliko puta tjedno, 5 - svaki dan), pri čemu je kao vremenski okvir postavljena godina dana. Pitanje kojim je ispitivana kulturna participacija glasilo je: „Koliko ste često u zadnjih 12 mjeseci u slobodno vrijeme radili dolje navedeno?"

\section{Rezultati}

Prije nego što iznesemo rezultate istraživanja kulturne participacije, bitno bi bilo nešto više reći o prostoru, odnosno o novostambenim naseljima i lokacijama u kojima ispitanici žive. Osnovna karakteristika novostambenih naselja u gradu Zagrebu ta je što su najčešće nastala tzv. privatnim tipom gradnje u tranzicijskom periodu na rubnim dijelovima grada. Privatizacija i komercijalizacija stanovanja jedan je od najvećih pokazatelja prijelaza na novi politički i ekonomski sustav, u kojem se i područje stanovanja prepustilo tzv. tržištu, a posljedice toga nastojale su se istražiti ovdje navedenim istraživanjem. Posljedice možemo vidjeti svakodnevno na razini njihove objektivne opremljenosti, koja je pokazala kako su tim stambenim lokacijama stanovnici samo djelomično zadovoljni. Međutim oni su subjektivno znatno zadovoljniji, a u prilog tome govori činjenica što su to stanovi kupljeni na novim i atraktivnim lokacijama, te je subjektivni dojam o njima ipak bolji od objektivnih pokazatelja. Riječ je o naseljima u kojima „kvaliteta života nije na zavidnoj i zadovoljavajućoj razini“, za razliku od manjih gradova Zagrebačke županije, koji su opremljeniji za svakodnevni život (Svirčić Gotovac, 2015.:8). Gradovi Zagrebačke županije (Samobor, Zaprešić i Velika Gorica) spadaju u tzv. satelitske gradove i naselja, a naseljava ih manji broj stanovnika (10.000 - 80.000). Oni se, iako preuzimaju neke značajke glavnoga grada u organizaciji svakodnevnog života (zapošljavanje, pružanje usluga itd.), zbog zadovoljavanja ostalih potreba nalaze u stalnoj interakciji sa Zagrebom (Svirčić Gotovac, 2015.). Niska opremljenost novosagrađenih naselja grada Zagreba podrazumijeva da ona nemaju u dovoljnoj mjeri zastupljene sadržaje koji odgovaraju povećanim potrebama novih stanovnika, kao što su vrtići, škole, igrališta, stanice javnog prijevoza, ambulante i sl., a također su slabo zastupljeni sadržaji kulture širokog spektra, odnosno porast broja stanovnika u naseljima nije pratio razvoj niti komunalne niti kulturne infrastrukture, te je on većinom ostao na razini nekadašnjih starijih naselja. Starija naselja stoga ostaju dodatno pritisnuta povećanim potrebama pridošlih stanovnika. Nositelji najfrekventnijih kulturnih zbivanja u gradovima Zagrebačke županije uglavnom su nekadašnja narodna sveučilišta, a današnja pučka otvorena učilišta. U Zagrebu pak postoje kvartovski centri za kulturu, koji relativno zadovoljavaju kulturne potrebe pojedinih grupacija stanovnika, dok je velika većina visokih kulturnih institucija i programa zastupljena isključivo u centru grada.

Istražujući sekundarni indeks susjedstva za sva četiri grada u ovom istraživanju, tj. višu razinu opremljenosti naselja specijaliziranim trgovinama, ambulantama, kulturnim centrima, tržnicama, knjižnicama itd., utvrđeno je da je u svim četirima gradovima prisutan lošiji nivo opremljenosti, odnosno samo $23,4 \%$ novostambenih na- 
selja ima dobar sekundarni indeks (Svirčić Gotovac, 2015.:62). Unatoč tome 82,2\% ukupnog broja ispitanika zadovoljno je ili izrazito zadovoljno lokacijom na kojoj stanuje. Posebno treba napomenuti kako je stanovanje u satelitskim gradovima podosta atraktivno, a pojedine novosagrađene lokacije karakteriziraju skupi stambeni i komercijalni prostori.

Tablica 1.

Učestala kulturna participacija u novostambenim naseljima (\%)

\begin{tabular}{|c|c|}
\hline Kulturne aktivnosti & Učestalo (\%) \\
\hline Gledali televiziju, DVD, video & 73,7 \\
\hline Provodili vrijeme na internetu/računalu & 72,4 \\
\hline Slušali glazbu & 60,1 \\
\hline Slušali radio & 56,2 \\
\hline Čitali dnevne novine, tjednike & 36,0 \\
\hline Čitali knjigu & 16,6 \\
\hline Ciljano pratili programe kulturne programe na televiziji i radiju & 12,7 \\
\hline Bavili se fizičkim aktivnostima (sport, teretana, šetnje, aktivnosti u prirodi) & 12,0 \\
\hline $\begin{array}{l}\text { Bavili se nekom umjetničkom aktivnošću (kiparstvo, slikanje, crtanje, ples, } \\
\text { pjevanje, sviranje, pisanje, gluma i sl.) }\end{array}$ & 3,6 \\
\hline Bavili se ručnim radom, vezenjem, stolarskim radovima i slično & 1,0 \\
\hline Posjetili kino & 0,6 \\
\hline Posudili knjigu/časopis, CD ili DVD u knjižnici & 0,6 \\
\hline Pohađali tečajeve stranih jezika ili druge obrazovne programe & 0,6 \\
\hline Otišli na koncert & 0,3 \\
\hline Prisustvovali sportskim događanjima kao gledatelj/ica & 0,3 \\
\hline $\begin{array}{l}\text { Pohađali organizirane umjetničke tečajeve i radionice (sviranje, slikanje, } \\
\text { kreativno pisanje, ples i slično) }\end{array}$ & 0,3 \\
\hline Sudjelovali u radu KUD-a (kulturno-umjetničkog društva) & 0,3 \\
\hline Posjetili muzej ili galeriju & - \\
\hline Posjetili kazalište (dramska, operna, baletna, plesna predstava) & - \\
\hline Posjetili javno predavanje, tribinu, predstavljanje knjige i slično & - \\
\hline Posjetili neku kulturnu znamenitost (spomenici, zgrade, crkve, dvorci i sl.) & - \\
\hline
\end{tabular}


Rezultate koji upućuju na širi spektar aktivnosti u slobodnom vremenu (uključena 21 aktivnost) prikazali smo u tablici 1. tako da smo grupirali odgovore (3 - nekoliko puta mjesečno, 4 - nekoliko puta tjedno i 5 - svaki dan). Od svih predloženih aktivnosti stanovnici novostambenih naselja najviše su gledali televiziju, DVD i video $(73,7 \%)$ te provodili vrijeme za računalom ili na internetu $(72,4 \%)$. Među frekventnijim aktivnostima nalaze se i slušanje glazbe $(60,1 \%)$ i radija $(56,2 \%)$, čitanje dnevnih novina i tjednika $(36,0 \%)$ te čitanje knjiga $(16,6 \%)$. Skoro su podjednako zastupljeni ciljano praćenje programa iz kulture na televiziji i radiju (12,7\%) i bavljenje fizičkim aktivnostima kao što su sport, teretana, šetnje i aktivnosti u prirodi (12,0\%), međutim prisustvovanje sportskim događanjima kao gledatelj/gledateljica slabo je zastupljeno $(0,3 \%)$. Umjetničkom aktivnošću učestalo se bavilo tek 3,6\% ispitanika, dok se primijenjenim aktivnostima (ručni rad, vezenje, stolarski radovi i sl.) učestalo bavilo samo $1 \%$ ispitanika. Posudba knjiga i časopisa kao i CD-a i DVD-a u knjižnicama nije učestalog karaktera kao ni pohađanje tečajeva stranih jezika i ostalih obrazovnih programa (obje aktivnosti zastupljene su s 0,6\%). Aktivnosti kao što su posjeti kinu i odlasci na koncert zastupljeni su s neznatnom učestalošću na dnevnoj, tjednoj ili mjesečnoj razini, dok posjeti muzejima ili galerijama, kazalištima, javnim predavanjima, tribinama, predstavljanju knjiga ili posjeti kulturnim znamenitostima nisu uopće među često zastupljenim aktivnostima, čak ni na mjesečnoj razini. Jedan, izrazito malen postotak ispitanika pokazuje interes za pohađanje organiziranih umjetničkih tečajeva $(0,3 \%)$, dok ih jednako malo sudjeluje u radu amaterskih kulturno-umjetničkih društava $(0,3 \%)$.

Adekvatnost uzorka za primjenu faktorske analize provjerena je Kaiser-Meyer-Olkin testom (.814), koji upućuje na opravdanost ove analize. Faktorska analiza provedena je metodom analize glavnih komponenata. Prvotno je izlučeno sedam faktora, od kojih su tri bila neadekvatna za daljnju analizu. Kako bi se ostvarilo načelo jednostavne strukture, za rotaciju su uz primjenu Varimax kriterija zadržana četiri faktora, te je dobivena matrica faktorske strukture prikazana u tablici 2. Rezultati su pokazali da četiri dobivena faktora zajedno tumače $57,2 \%$ varijance.

Prvi faktor nazvali smo participacija u visokoj kulturi, a čine ga aktivnosti koje se odnose na posjete muzeju ili galeriji, koncertima, kazalištima, kinu, kulturnim znamenitostima i javnim predavanjima. Takva faktorska struktura govori u prilog postojanju elitnog obrasca kulturne potrošnje.

Na drugom faktoru, koji je nazvan čitanje i konzumacija kulturnih programa, nalaze se dvije aktivnosti vezane uz knjige (čitanje i posudba knjiga u knjižnici). Također, na tom se faktoru nalazi ciljano praćenje kulturnih programa na televiziji i radiju, što potvrđuje postojanje interesa za praćenje širokog spektra kulture (od praćenja filma i glazbe do specijaliziranih emisija o kulturi). 
Tablica 2.

Struktura kulturne participacije

\begin{tabular}{|c|c|c|c|c|}
\hline Kulturna participacija & $\begin{array}{c}\text { Faktor } 1 \\
\text { Participacija u } \\
\text { visokoj kulturi }\end{array}$ & $\begin{array}{c}\text { Faktor } 2 \\
\text { Čitanje i } \\
\text { konzumacija } \\
\text { kulturnih } \\
\text { programa }\end{array}$ & $\begin{array}{c}\text { Faktor } 3 \\
\text { Aktivno } \\
\text { bavljenje } \\
\text { umjetničkim i } \\
\text { primijenjenim } \\
\text { aktivnostima }\end{array}$ & $\begin{array}{c}\text { Faktor } 4 \\
\text { Auditivna } \\
\text { kultura }\end{array}$ \\
\hline Posjet muzeju ili galeriji &, 753 & & & \\
\hline Odlazak na koncert &, 740 & & & \\
\hline Posjet kazalištu & ,706 & & & \\
\hline Posjet kinu & ,647 & & & \\
\hline Posjet kulturnim znamenitostima &, 527 & & & \\
\hline $\begin{array}{l}\text { Posjet javnom predavanju, tribini, } \\
\text { predstavljanju knjiga itd. }\end{array}$ &, 512 & ,396 & & \\
\hline Čitanje knjige & & ,823 & & \\
\hline $\begin{array}{l}\text { Posudba knjiga/časopisa, CD-a i } \\
\text { DVD-a u knjižnici }\end{array}$ & &, 667 & & \\
\hline $\begin{array}{l}\text { Ciljano praćenje kulturnih } \\
\text { programa na televiziji ili radiju }\end{array}$ & &, 549 & & ,396 \\
\hline $\begin{array}{l}\text { Aktivno bavljenje nekom } \\
\text { umjetničkom aktivnošću (kiparstvo, } \\
\text { slikanje, crtanje, ples, pjevanje, } \\
\text { sviranje, pisanje, gluma i sl.) }\end{array}$ & & & ,781 & \\
\hline $\begin{array}{l}\text { Bavljenje ručnim radom, vezenjem, } \\
\text { stolarskim radovima i sl. }\end{array}$ & & & ,703 & \\
\hline $\begin{array}{l}\text { Pohađanje organiziranih } \\
\text { umjetničkih tečajeva i radionica } \\
\text { (sviranje, slikanje, kreativno } \\
\text { pisanje, ples i sl.) }\end{array}$ & & & ,662 & \\
\hline Slušanje radija & & & & ,852 \\
\hline Slušanje glazbe & & & &, 749 \\
\hline Postotak zajedničke varijance & 27,63 & 11,38 & 10,14 & 8,01 \\
\hline
\end{tabular}

Treći faktor, aktiuno bavljenje umjetničkim i primijenjenim aktivnostima, upućuje na postojanje aktivne kulturne participacije koja uključuje osobno bavljenje umjetnošću (kiparstvo, slikanje, crtanje, ples, pjevanje, sviranje, pisanje, gluma i slično), bavljenje primijenjenim vještinama kao što su ručni rad, vezenje, stolarski radovi i slično te obrazovanje kroz pohađanje različitih tečajeva i radionica na kojima se uče ili dodatno unaprjeđuju već stečene umjetničke vještine (npr. sviranje, slikanje, kreativno pisanje, ples, gluma i slično).

Četvrti je faktor nazvan auditiona kultura jer uključuje čestice koje upućuju na praćenje raznolikih radijskih sadržaja kao i slušanje glazbe. Riječ je o pasivnoj kulturnoj participaciji, koja vjerojatno uključuje praćenje različitih sadržaja popularne, a vjerojatno i sadržaja visoke kulture budući da se na tom faktoru nalazi i čestica ciljanog praćenja kulturnih programa na televiziji i radiju. 
Nakon faktorizacije dobivene latentne dimenzije pretvorene su u aditivne skale s obzirom na to da je Cronbachov koeficijent pouzdanosti bio zadovoljavajući (tablica 3.). Prosječne vrijednosti na skali aktivnog bavljenja umjetničkim i primijenjenim aktivnostima $(\mathrm{M}=1,31, \mathrm{sd}=, 91)$ i skali participacije u visokoj kulturi $(\mathrm{M}=1,78, \mathrm{sd}$ $=, 48)$ niske su, nešto veća prosječna vrijednost iskazuje se na skali čitanja i konzumacije kulturnih programa $(M=2,48, s d=0,91)$, dok je najviša na skali auditivne kulture $(\mathrm{M}=4,18, \mathrm{sd}=1,01)$. Povezanost skala sa sociodemografskim obilježjima ispitivana je analizom varijance ili t-testom (tablica 4.).

Tablica 3.

Aritmetička sredina, standardna devijacija i Cronbachov koeficijent pouzdanosti skala

\begin{tabular}{|l|c|c|c|}
\hline Skala & Aritmetička sredina & Standardna devijacija & Cronbach koef. \\
\hline $\begin{array}{l}\text { Skala participacije u visokoj } \\
\text { kulturi }\end{array}$ & 1,78 &, 48 & 0,77 \\
\hline $\begin{array}{l}\text { Skala čitanja i konzumacije } \\
\text { kulturnih programa }\end{array}$ & 2,48 &, 91 & 0,61 \\
\hline $\begin{array}{l}\text { Skala aktivnog bavljenja } \\
\text { umjetničkim i primijenjenim } \\
\text { aktivnostima }\end{array}$ & 1,31 &, 56 & 0,56 \\
\hline Skala auditivne kulture & 4,18 & 1,01 & 0,59 \\
\hline
\end{tabular}

Sa skalom participacije u visokoj kulturi statistički su značajno povezane sociodemografske varijable: radni status $(\mathrm{F}=10,259, \mathrm{p}<, 01)$, školska sprema $(\mathrm{F}=2,817$, p $<, 01)$, zanimanje ispitanika $(\mathrm{F}=1,923, \mathrm{p}<, 01)$ te prosječni mjesečni prihod kućanstva $(\mathrm{F}=4,828, \mathrm{p}<, 01)$. Zaposleni ispitanici češće konzumiraju taj obrazac kulturne participacije u odnosu na ostale (domaćice, umirovljenici i drugi). Prema školskoj spremi ispitanici više i visoke stručne spreme te nositelji akademskih stupnjeva značajno više konzumiraju sadržaje visoke kulture od ispitanika koji imaju (ne)završenu osnovnu školu. Nadalje, stručnjaci i rukovoditelji značajno češće participiraju u tom kulturnom obrascu od ispitanika koji rade kao službenici ili obnašaju kvalificirana i nekvalificirana zanimanja. S obzirom na prihode, na skali visoke kulture također značajno češće participiraju ispitanici s 15.000 kn i više prosječnih mjesečnih prihoda u kućanstvu od onih čiji su prosječni mjesečni prihodi kućanstva do 5.000 kn.

Na skali čitanja i konzumacije kulturnih programa (t-test $=-3,541, \mathrm{p}<, 01)$ statistički značajno učestalije participiraju žene. Osim toga ta je skala značajno povezana $s$ dobi $(\mathrm{F}=3,444, \mathrm{p}<, 01)$, školskom spremom $(\mathrm{F}=4,553, \mathrm{p}<, 01)$ i bračnim statusom $(\mathrm{t}$-test $=-2,872, \mathrm{p}<, 011)$. Pritom ispitanici u dobi $41-50$ godina statistički značajno češce koriste taj obrazac kulturne participacije od ispitanika u dobi 30 - 40 godina. Ispitanici s višom, visokom stručnom spremom i akademskim stupnjevima značajno više sudjeluju u tom tipu kulturne konzumacije od ispitanika nižih stručnih sprema. Također, značajno više prosječne vrijednosti na toj skali iskazuju ispitanici koji žive u bračnoj zajednici u odnosu na samce.

Skala aktivnog bavljenja umjetničkim i primijenjenim aktivnostima značajno je povezana samo sa spolom, pri čemu žene značajno češće sudjeluju u takvom obrascu (t-test $=2,905, \mathrm{p}<, 01)$. 
Skala auditivne kulture nije značajno povezana ni s jednim ispitivanim sociodemografskim obilježjem.

Kada je riječ o sociodemografskim varijablama, valja napomenuti da se školska sprema oca kao i grad u kojem žive ispitanici nisu pokazali statistički značajno povezani ni s jednom od četiriju skala.

Tablica 4.

Obrasci kulturne participacije s obzirom na odabrana sociodemografska obilježja (prosječne vrijednosti, F-test, t-test)

\begin{tabular}{|c|c|c|c|}
\hline Socio-demografski pokazatelji & $\begin{array}{c}\text { Skala } 1 \\
\text { Participacija u } \\
\text { visokoj kulturi }\end{array}$ & $\begin{array}{c}\text { Skala } 2 \\
\text { Čitanje } \mathrm{i} \\
\text { konzumacija } \\
\text { kulturnih programa }\end{array}$ & $\begin{array}{c}\text { Skala } 3 \\
\text { Aktivno bavljenje } \\
\text { umjetničkim i } \\
\text { primijenjenim } \\
\text { aktivnostima }\end{array}$ \\
\hline Spol & & t-test $=-3,54^{*}$ & t-test $=-2,91^{*}$ \\
\hline 1. Muški & & 2,29 & 1,22 \\
\hline 2. Ženski & & 2,65 & 1,39 \\
\hline Dob & & $\mathbf{F}=3,44^{*}$ & \\
\hline 1. $18-29$ & & 2,26 & \\
\hline 2. $30-40$ & & 2,31 & \\
\hline 3. $41-50$ & & $2,72 * *(3-2)$ & \\
\hline 4. $51-60$ & & 2,57 & \\
\hline 5. $61-70$ & & 2,76 & \\
\hline 6. $71 \mathrm{i}$ više & & 2,88 & \\
\hline Radni status & $\mathbf{F}=10,26^{*}$ & & \\
\hline 1. Zaposleni & $1,85^{* *}(1-3)$ & & \\
\hline 2. Nezaposleni & 1,66 & & \\
\hline 3. Ostalo & 1,56 & & \\
\hline Školska sprema & $\mathbf{F}=\mathbf{2 , 8 1 *}$ & $\mathrm{F}=4,55^{*}$ & \\
\hline 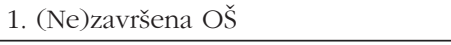 & 1,17 & 2,17 & \\
\hline 2. SSS i srodne škole & 1,57 & 2,29 & \\
\hline 3. VŠS, VSS i više & $1,92^{* * *}(3-1)$ & $2,60 * *(3-2)$ & \\
\hline Zanimanje & $\mathbf{F}=19,91 *$ & & \\
\hline 1. KV i NKV & 1,56 & & \\
\hline 2. Službenici & 1,71 & & \\
\hline 3. Stručnjaci i rukovoditelji & $1,94^{* *}(3-1)(3-2)$ & & \\
\hline Bračni status & & t-test $=-2,87^{*}$ & \\
\hline 1. Ne živi u bračnoj zajednici & & 2,40 & \\
\hline 2. Živi u bračnoj zajednici & & 2,75 & \\
\hline Prosječni mjesečni prihod kućanstva & $\mathbf{F}=4,83^{*}$ & & \\
\hline 1. do $5.000 \mathrm{kn}$ & 1,62 & & \\
\hline 2. $5.001-9.999 \mathrm{kn}$ & 1,71 & & \\
\hline 3. $10.000-14.999$ & 1,82 & & \\
\hline 4. 15.000 i više & $1,95 * *(4-1)$ & & \\
\hline
\end{tabular}

*p $<, 01,{ }^{* *} \mathrm{p}<, 05$ 


\section{Diskusija i zaključci}

Ovo istraživanje potvrđuje postojanje nekoliko kulturnih obrazaca prisutnih u teoriji o kulturnoj participaciji, što se u prvom redu odnosi na obrazac participacije u visokoj kulturi. Imajući u vidu teorijske postavke Bourdieua (2011.), kulturni i ekonomski kapital značajno uvećavaju kulturno participiranje ili se, kako kažu Widdop i Cutts (2012.), klasa i obrazovanje pokazuju konstantnim prediktorima kulturne participacije. Obrazac participacije u visokoj kulturi prepoznat u ovom istraživanju značajnije uključuje visokoobrazovane ispitanike, stručnjake i rukovoditelje i one ispitanike čiji prosječni mjesečni kućni budžet iznosi 15.000 kn i više. Do sličnih uvida dolazi i istraživanje Hadžibulić (2012.) o sociodemografskim osobinama posjetitelja Opere Narodnog pozorišta u Beogradu, prema kojemu su u opernoj publici najviše zastupljene žene, osobe visokog obrazovanja, stručnjačkih zanimanja i visokog materijalnog standarda. U ovom istraživanju nije se potvrdila pretpostavka o tome da su žene češće konzumentice visoke kulture od muškaraca, iako se to očekivalo (DiMaggio, 2004.; Kane, 2004.; Christin, 2012.). Postojanje elitnog obrasca kulturne participacije potvrđeno je i u nizu domaćih istraživanja koja su se bavila sličnom tematikom na različitim uzorcima (Tonković i sur., 2017.; Ilišin, 2014.; Tonković, Krolo i Marcelić, 2014.).

S obzirom na to da u hrvatskim okvirima visoko obrazovanje ne osigurava najbolje plaćene poslove (Tomljenović, Hendija i Razović, 2011.), može se pretpostaviti kako mnogi svoj kulturni kapital ne mogu pretvoriti u ekonomski, te su im kulturni sadržaji zbog relativne skupoće jednostavno nedostupni. To se pogotovo odnosi na loš socijalni status umirovljenika, od kojih neki, unatoč posjedovanju kulturnog kapitala, ne mogu participirati u kulturnim događanjima (distinkcija u odnosu na zaposlene ispitanike potvrđena je u ovom istraživanju).

Pretpostavka prema kojoj će rezidencijalni status biti od važnosti prilikom participacije u visokoj kulturi nije se potvrdila. Iako su ispitanici iz Zagreba, zbog nešto manje prostorne distance, u mogućnosti doći do središta grada u kojem je koncentrirana visoka kulturna ponuda u relativno kraćem vremenu, njihova se participacija ne razlikuje od one ispitanika iz Samobora, Velike Gorice ili Zaprešića. Izgleda stoga da ce obrazovaniji i, prema našim uvidima, bogatiji stanovnici učestvovati u kulturnim zbivanjima bez obzira na to o kojoj je novostambenoj lokaciji riječ. Svakako treba ponovno naglasiti kako stanovnici zagrebačkih novoizgrađenih naselja i lokacija imaju sličnu ili čak lošiju kvalitetu života u odnosu na stanovnike satelitskih gradova (Svirčić Gotovac, 2015.). Bi li bolja prometna povezanost sa središtem ili bolja kulturna infrastruktura u naseljima doprinijela i u kojoj mjeri participaciji, ostaje pitanje spekulativne naravi ne samo u vezi posjećivanja događanja visokog ranga nego i u vezi potrošnje ostalih kulturnih sadržaja. No zanimljivo je spomenuti kako se upravo Zagreb i njegova okolica (prema analizi rezultata Eurobarometra iz 2013. godine) nalaze među rijetkim hrvatskim regijama koje karakteriziraju nadprosječni indeksi kulturne potrošnje (Tonković i sur., 2017.). Taj nalaz svakako ne čudi s obzirom na to da je ipak riječ o najurbaniziranijim i najrazvijenijim prostorima Hrvatske. U europskim okvirima, međutim, kulturna potrošnja stanovnika Hrvatske manja je od europskog prosjeka (Tonković i sur., 2017.). 
Drugi utvrđeni kulturni obrazac, „čitanje i konzumacija kulturnih programa“, kao i treći, „aktivno bavljenje umjetničkim i primijenjenim aktivnostima“, govore u prilog potvrdi hipoteze o značajnoj povezanosti roda i kulture (DiMaggio, 2004.; Upright, 2004.).

Žene su povezane s obrascem čitanja, što je u skladu s rezultatima drugih istraživanja (Zill i Wingle, 1988.; Knulst i Kraaykamp, 1998., Tonković i sur., 2017.). Također, prema rezultatima Eurostata, u Hrvatskoj su 2007. godine žene bile zastupljene u čitalačkoj publici sa 60\%, dok su u nekim zemljama kao što su Švedska i Finska iste godine bile zastupljene i s oko 90\% (Eurostat, 2016.).

Čitateljice u tom obrascu spadaju u srednju generaciju iznad četrdesete godine života. Šire gledano, dobnih pravila nema. Naime u nekim zemljama zastupljeniji su mlađi, dok u drugima prevladavaju stariji čitatelji/ce. Prema rezultatima američke savezne agencije za umjetnost i kulturu National Endowment for the Arts (2007.), dobne se kohorte čitatelja mijenjaju; na primjer 2004. godine najviši postotak čitatelja književnosti nalazio se u dobnoj skupini 45 - 54 godine, dok je početkom 1980-ih najviši broj čitatelja bio u dobnoj kohorti 18 - 34 godine. Zill i Wingle (1988.) u svom su radu s temom o tome tko čita književnost utvrdili kako su nadreprezentirane žene, visokoobrazovani, bijelci i sredovječni ljudi. Čitalačke navike, međutim, povezane su i s obrazovanjem (Zill i Wingle, 1988.); što su ljudi obrazovaniji, naprosto više čitaju, što potvrđuju i naši rezultati. Osim toga obrazac čitanja potvrđuje postojanje lokalne kulturne potrošnje usmjerene k sadržajima u susjedstvu (posuđivanje knjiga, CD-a i DVD-a u obližnjim knjižnicama).

Objašnjenje toga zašto žene koje žive u braku čitaju više ulazi u srž razmatranja rodnih identiteta, ali i pitanja što se događa s kulturnim kapitalom prilikom ulaska u brak. DiMaggio (2004.) smatra kako prilikom ulaska u brak ne postoji nužni proces akumulacije kulturnog kapitala. Prema uvidima Teppera (1998.) u mnogobrojne teorijske i empirijske izvore koji razmatraju rodne razlike u kulturi, postoje evidentni dokazi da se dječaci, za razliku od djevojčica, ne socijaliziraju za čitanje fikcije. Čitanje se smatra ženskom aktivnošću i ono se odvija u kući, traži mirovanje, koncentraciju te fizičku neaktivnost.

Ista logika objašnjenja vrijedi i za umjetničko izražavanje (DiMaggio, 2004.). Umjetnička je socijalizacija dio rodne socijalizacije, te se smatra primjerenijom djevojčicama nego dječacima jer one na taj način stječu kulturni kapital koji bi se u kasnijim godinama života mogao pretvoriti u ekonomski. Istraživanja, međutim, pokazuju kako su pripadnici srednjih klasa skloni investirati u kulturni kapital djevojčica (npr. formalno i neformalno obrazovanje), koji uslijed kasnije diskriminacije daleko premašuje njihova stečena zanimanja i zaradu na tržištu rada (DiMaggio, 2004.).

Na kraju ostaje još komentirati obrazac auditivne kulture. Taj obrazac nije bio povezan ni s jednim sociodemografskim obilježjem, ali je prema prosječnim vrijednostima vrlo zastupljen u ukupnom uzorku. Rezultat upućuje na popularnost slušanja glazbe i radijskih programa, ali i usmjerenost na televizijske i radijske kulturne programe. Nije to čudno, budući da je glazbena industrija, uz filmsku, postala moćno 
žarište kulturne potrošnje, ali i iskazivanja životnog stila (Krolo, Marcelić i Tonković, 2016.). Nadalje, slušanje glazbe krije u sebi uporabu novih medija te različite načine dobavljanja glazbenih sadržaja (Tepper i Hargittai, 2009.), čemu su sklonije mlađe dobne skupine (Tonković i sur., 2017.). Kako bi popularnost slušanja radija trebalo zasebno ispitivati, valja samo naglasiti činjenicu da se u longitudinalnoj analizi o načinu provođenja slobodnog vremena u mladih utvrdio izrazit pad slušanosti radijskog programa a u korist upotrebe novih medija, posebno Interneta (Ilišin, 2014.). Nadalje, slušanje glazbe i radija ne govori puno o glazbenom ukusu ispitanika jer čak i usmjereni kulturni programi na televiziji i radiju mogu biti povezani s nižim kulturnim ukusom vezanim uz emitiranje popularnih i komercijalnih sadržaja. Vrlo sofisticirana istraživanja na međunarodnom nivou nisu komparabilna s dobivenim rezultatima.

Iako u ovom istraživanju nije posebno ispitivana eventualna participacija u kulturnim sadržajima putem računala/Interneta, nego je samo iskazana učestalost, vidljiva je njezina visoka zastupljenost. Taj podatak može upućivati na činjenicu kako već odavno nove medijske forme koje podržavaju i aktivnu i pasivnu kulturnu participaciju nadmašuju tradicionalne (Foote, 2002.), pogotovo među mladim generacijama, te su promijenile navike, omogućile potrošnju različitih kulturnih sadržaja i unaprijedile mnogobrojne forme besplatnog obrazovanja vezane uz aktivnu participaciju.

Preporuke za daljnja istraživanja idu u mnogim smjerovima: od potrebe praćenja opće kulturne participacije na reprezentativnim uzorcima do istraživanja novih oblika kulturnih participacija, bez obzira na to radi li se o razlikama među omnivorima ili o pojavi takvih oblika participacija koje spadaju u privatnu potrošnju, a odvijaju se unutar doma, automobila, poslovnog okruženja i sl. Za tako usmjerena istraživanja metodologija kojom se istražuje kulturna participacija trebala bi biti kompleksnije naravi.

S obzirom na jačanje društvene zainteresiranosti za procese inkluzivnosti značaj lokalne kulturne participacije svakako raste, pogotovo gledano iz perspektive (ne) opremljenosti novostambenih naselja. U tom bi smislu bilo bitno evaluirati i poticati programe centara za kulturu kao i ostale kulturne programe organizacija civilnog društva usmjerene kvalitetnijem zadovoljavanju lokalnih potreba - što se javne kulturne potrošnje tiče. Prostorno dostupnijim programima omogućilo bi se svima, a pogotovo nižim slojevima društva, lakše stjecanje i/ili nadogradnja kulturnog kapitala. 


\section{Literatura}

1. Bourdieu, P. (1986). The forms of capital. https://www.marxists.org/reference/ subject/philosophy/works/fr/bourdieu-forms-capital.htm. (Pregledano 27. travnja 2017.)

2. Bourdieu, P. (2011 [1979/1982]). Distinkcija. Društvena kritika suđenja. Zagreb: Antibarbarus.

3. Brook, O. (2013). Reframing models of arts attendance: Understanding the role of access to a venue. The case of opera in London. Cultural Trends, 22 (2): 97-107.

4. Brook, O. (2016). Spatial equity and cultural participation: how access influences attendance at museums and galleries in London, Cultural Trends. Cultural Trends, 25 (1): 21-34.

5. Christin, A. (2012). Gender and highbrow cultural participation in the United States. Poetics, 40: 423-443.

6. Cutts, D. and Widdop, P. (2016). Reimagining omnivorousness in the context of place. Journal of Consumer Culture, 0 (0): 1-24.

7. Čolić, S. (2002). Kultura i povijest. Socio-kulturno antropološki aspekti hijerarbizacije kulture. Zagreb: Hrvatska sveučilišna naklada.

8. Delrieu, V. and Gibson, L. (2017). Libraries and the geography of use: how does geography and asset "attractiveness" influence the local dimensions of cultural participation?. Cultural Trends, 26 (1): 18-33.

9. DiMaggio, P. (2004). Preface. Gender, networks, and cultural capital. Poetics, 32: 99-103.

10. DiMaggio, P. and Mukhtar, T. (2004). Arts participation as cultural capital in the United States, 1982-2002: Signs of decline?. Poetics, 32: 169-194.

11. Eurostat (2016). Culture statistics. Luxembourg: European Union. http://ec.europa. eu/eurostat/documents/3217494/7551543/KS-04-15-737-EN-N.pdf/648072f363c4-47d8-905a-6fdc742b8605. (Pregledano 20. svibnja 2017.)

12. Foote, J. A. (2002). Cultural consumption and participation. Canadian Journal of Communication, 27: 309-220.

13. Hadžibulić, S. (2012). Jedno sociološko istraživanje publike Opere Narodnog pozorišta u Beogradu. Filozofija i društvo, 23 (3): 295-312.

14. Ilišin, V. (2014). Zanemarena škola života: Slobodno vrijeme i interesi studenata, u: Ilišin, V. (Ur.). Sociološki portret hrvatskih studenata. Zagreb: Institut za društvena istraživanja u Zagrebu.

15. Kane, D. (2004). A network approach to the puzzle of women's cultural participation. Poetics, 32: 105-127.

16. Katunarić, V. i Cvjetičanin, B. (Ur.) (1998). Kulturna politika Republike Hrvatske: nacionalni izvještaj. Zagreb: Ministarstvo kulture Republike Hrvatske.

17. Knulst, W. and Kraaykamp, G. (1998). Trends in leisure reading: Forty years of research on reading in the Netherlands. Poetics, 26: 21-41.

18. Krištofić, B. (2015). Kvaliteta Života i tranzicija. Sociološka rekonstrukcija na primjeru Zagreba, u: Svirčić Gotovac, A. i Zlatar, J. (Ur.). Kvaliteta života u novostambenim naseljima i lokacijama u zagrebačkoj mreži naselja. Zagreb: Institut za društvena istraživanja u Zagrebu, 117-147.

19. Krolo, K.; Marcelić, S. i Tonković, Ž. (2016). Roditeljski kulturni kapital kao odrednica kulturnih preferencija mladih. Društvena istraživanja, 25 (3): 329-351. 
20. Leguina, A. and Miles, A. (2017). Fields of participation and lifestyle in England: revealing the regional dimension from a reanalysis of the Taking Part Survey using Multiple Factor Analysis. Cultural Trends, 26 (1): 4-17.

21. Miles, A. (2016). Telling tales of participation: exploring the interplay of time and territory in cultural boundary work using participation narratives. Cultural Trends, 25 (3): 182-193.

22. Miles, A. and Ebrey, J. (2017). The village in the city: participation and cultural value on the urban periphery. Cultural Trends, 26 (1): 58-69.

23. National Endowment for the Arts (2007). To Read or Not To Read A Question of National Consequence. Washington: National Endowment for the Arts. https:// www.arts.gov/sites/default/files/ToRead.pdf. (Pregledano 30. svibnja 2017.)

24. Relish, M. (1997). It's not all education: Network measures as sources of cultural competency. Poetics, 25 (2): 121-139.

25. Svirčić Gotovac, A. (2015). New Housing Estates in the Settlement Network of Zagreb - Community Infrastructure, u: Svirčić Gotovac, A. i Zlatar, J. (Ur.). Kvaliteta života u novostambenim naseljima i lokacijama u zagrebačkoj mreži naselja. Zagreb: Institut za društvena istraživanja u Zagrebu, 45-75.

26. Peterson, A. R. and Kern, R. M. (1996). Changing Highbrow Taste: From Snob to Omnivore. American Sociological Review, 61 (5): 900-907.

27. Švob-Đokić, N. (2010). Kulturni opstanak, nestanak ili transformacija, u: ŠvobĐokić, N. (Ur.). Kultura/multikultura. Zagreb: Naklada Jesenski i Turk, Hrvatsko sociološko društvo.

28. Tepper, S. J. (1998). Why Do More Women Read Fiction? Center for Arts and Cultural Policy Studies: Princeton University. https://www.princeton.edu/čartspol/ workpap/WP06\%20-\%20Tepper.pdf. (Pregledano 18. svibnja 2017.)

29. Tepper, S. J. and Hargittai, E. (2009). Pathways to music exploration in a digital age. Poetics, 37: 227-249.

30. Tonković, Ž.; Krolo, K. i Marcelić, S. (2014). Kulturna potrošnja i glazbene preferencije mladih: razvoj tipologije na primjeru Zadra. Revija za sociologiju, 44 (3): $287-315$.

31. Tonković, Ž.; Marcelić, S. i Krolo, K. (2017). Kulturna potrošnja, društvene nejednakosti i regionalne razlike: istraživanje Eurobarometra u Hrvatskoj 2013. godine. Sociologija i prostor, 208 (2): 187-208.

32. Tomljenović, R.; Hendija, Z. i Razović, M. (2011). Domaća kulturna potražnja: analiza slučaja Splitsko-dalmatinske županije. Acta turistica, 23 (1): 27-48.

33. UNESCO (2012). Measuring cultural participation. Montreal, Quebec: UNESCOUIS. http://www.uis.unesco.org/culture/Documents/fcs-handbook-2-culturalparticipation-en.pdf. (Pregledano 17. svibnja 2017.)

34. Upright, C. B. (2004). Social capital and cultural participation: spousal influences on attendance at arts events. Poetics, 32: 129-143.

35. Zill, N. and Winglee, M. (1988). Who Reads Literature? Survey Data on the Reading of Fiction, Poetry, and Drama by U.S. Adults during the1980s. http://files. eric.ed.gov/fulltext/ED302812.pdf. (Pregledano 25. svibnja 2017.)

36. Widdop, P. and Cutts, D. (2012). Impact of place on museum participation. Cultural Trends, 21 (1): 47-66. 
Izvorni znanstveni rad

Mirjana Adamović

Institute for Social Research in Zagreb, Croatia

e-mail:mirjana@idi.hr

\title{
New Housing Estates in the Settlement Network of Zagreb - Cultural Participation of Residents
}

\begin{abstract}
This paper, using Bourdieu's theoretical framework, aims to research the cultural participation structure and how it is related to the social characteristics of respondents living in new housing estates in Zagreb and the neighbouring cities (Samobor, VelikaGorica and Zaprešić). The survey was conducted in 2014 on a target sample of 308 respondents. Factor analysis identified four dimensions of cultural participation: "participation in high culture", "reading and consumption of cultural programs", "active participation in artistic and applied art activities" and "auditory culture". In order to research the impact of selected sociodemographic characteristics on cultural participation, factors were transformed into additive scales and variance analysis and t-test were applied. Results show that the "participation in high culture" scale is correlated with education, work status, occupation of respondents and average monthly household income. The "reading and consumption of cultural programs" scale is connected with female gender, age, education and marital status, whereas the "active involvement in artistic and applied activities" scale is only connected with female gender. The scale of "auditory culture" is not related to any socio-demographic characteristics. This research confirms the importance of socioeconomic status in the consumption of high culture as well as the importance of gender in certain dimensions of cultural participation. Differences in cultural participation of Zagreb residents and residents of the neighboring cities have not been confirmed.
\end{abstract}

Key words: cultural participation, cultural capital, new housing estates and locations, gender. 